\title{
Perfusion Computed Tomography Scan Imaging in Differentiation of Benign from Malignant Parotid Lesions
}

\author{
Masume Niazi ${ }^{1}$ Maryam Mohammadzadeh² Kayvan Aghazadeh1® Hashem Sharifian ${ }^{3}$ \\ Ebrahim Karimi ${ }^{1}$ Madjid Shakiba $^{4}$ Maria Baniasadi $^{3}$ Benyamin Rahmaty ${ }^{1}$ Suzan Adel ${ }^{1}$ \\ Melorina Moharreri ${ }^{1}$
}

1 Department of Otorhinolaryngology, Otorhinolaryngology Research Center, Tehran University of Medical Sciences, Tehran, Iran

${ }^{2}$ Division of Neuroradiology, Department of Radiology, Amir Aalam Hospital, Tehran University of Medical Sciences, Tehran, Iran

${ }^{3}$ Department of Radiology, Amir Aalam Hospital, Tehran University of Medical Sciences, Tehran, Iran

${ }^{4}$ Advanced Diagnostic and Interventional Radiology Research Center (ADIR), Tehran University of Medical Sciences, Tehran, Iran

\begin{abstract}
Address for correspondence Kayvan Aghazadeh, MD, Department of Otorhinolaryngology, Otorhinolaryngology Research Center, Tehran University of Medical Sciences, Tehran 1416753955, Iran (e-mail: aghazadeh@sina.tums.ac.ir).
\end{abstract}

Int Arch Otorhinolaryngol 2020;24:e160-e169.

\begin{abstract}
Keywords

- computed tomography

- magnetic resonance imaging

- parotid neoplasms

- Warthin's tumor

- pleomorphic adenoma

Introduction The most common site of salivary gland tumors is the parotid gland. Computed tomography (CT), magnetic resonance imaging (MRI), and sonography are imaging modalities to differentiate benign from malignant parotid tumors.

Objective The aim of this study is the evaluation of the diagnostic value of perfusion CT for differentiating histological categorization of benign and malignant parotid tumors.

Methods A total of 29 patients with parotid neoplasms were enrolled in this study. Mean age and all CT perfusion variables (gradient and permeability, blood flow [BF], blood volume $[\mathrm{BV}]$, mean transit time [MTT], permeability surface [PS], maximum intensity projection [MIP], time-density curve [TDC], and time to peak [TTP]) were compared among three groups (malignant tumors [MTs], Warthin's tumor [WT] and pleomorphic adenomas [PA]). Results The mean age of the patients was $55.9 \pm 14.1$ (26-77), and 15 of them were male (51.7\%). Eleven lesions were PAs [37.9\%], 8 lesions were WTs (27.6\%0 and 10 lesions (34.5\%) were MTs (6 acinic cell carcinomas [ACCs], 3 adenocystic carcinomas [AdCCs], and 1 mucoepidermoid carcinoma [MEC]). The mean age of the patients with WTs was $62 \pm 7.5$ years; $52 \pm 14.2$ for patients with Pas, and $55.2 \pm 17.2$ for those with MTs $(p=0.32)$. The mean MIP was $122.7 \pm 12.2$ in WT, while it was $80.5 \pm 19.5$ in PA, and $76.2 \pm 27.1$ in MTs $(p<0.001)$; The mean MIP for WT was higher than for PAs and MTs; the values of MTs and PAs were not statistically different. The average of BF, BV, and curve peak were higher in WTs in comparison with the other two groups, and curve time 2 and TTP were higher in PAs in comparison with MTs.

Conclusion Based on this study, perfusion CT of the parotid gland and its parameters can distinguish between benign and malignant parotid masses.
\end{abstract}

received

September 22, 2018

accepted

July 8, 2019
DOI https://doi.org/

10.1055/s-0039-1697005. ISSN 1809-9777.
Copyright $\odot 2020$ by Thieme Revinter

Publicações Ltda, Rio de Janeiro, Brazil
License terms

(c) $(1) \$$ 


\section{Introduction}

Salivary gland neoplasms are relatively rare and make up 2 to $6.5 \%$ of head and neck tumors. ${ }^{1}$ Malignant lesions typically present after the age of 60 years, whereas benign lesions usually present when patients are older than 40 years. Benign neoplasms are more pronounced among women than in men, but malignant tumors are distributed equally between the sexes. ${ }^{2}$

The most common benign neoplasm of the parotid gland is the pleomorphic adenoma "(PA), which represents $~ 60 \%$ of all parotid neoplasms. Warthin's tumor (WT) is the second most common benign tumor, with an incidence of 15 to $20 \%$ of all parotid tumors. Malignant tumors (MTs) of the parotid gland are rare and have an incidence of $\sim 2$ to 3 cases per 100,000 individuals. Based on the evidence, $\sim 20$ to $30 \%$ of tumors of the parotid gland, $40 \%$ of submandibular, $50 \%$ of the minor salivary glands, and $90 \%$ of sublingual tumors are malignant lesions. The most common malignant tumor of the parotid is the mucoepidermoid carcinoma; other malignant lesions are: adenoid cystic carcinoma, squamous cell carcinoma, and adenocarcinoma. ${ }^{3}$

Imaging tests show some information, such as location (extracapsular or intracapsular tumors), superficial and deep lobe tumors, facial nerve and adjacent structures, the extension of the tumor, neural involvement, and nodal metastases.

Computed tomography and MRI are used routinely to evaluate head and neck tumors. Generally, benign tumors are more homogeneous, with visible margins, and malignant lesions have invisible margins and heterogeneous appearance. The biopsy of suspicious lesions is an essential step to confirm the diagnosis. Perfusion CT scan has recently been presented as a new modality to visualize neovascularization, which is one of the characteristic features of malignant tumors that allows growing at a rapid pace. ${ }^{4}$

Perfusion CT facilitates the evaluation of functional parameters in salivary gland neoplasms, such as tissue perfusion; besides, it can collect morphological information that a typical CT scan unable to provide. Perfusion CT measures microvascular density and vascular permeability with a variety of parameters; blood flow (blood flow), which measures the volume of blood passing through the tissue during the first passage; mean transit time (MTT) corresponds to the average time, in seconds, that red blood cells spend within a determinate volume of capillary circulation; blood volume, which is the volume of blood passing to the target tissue; tissue permeability, and, finally, the timedensity curve models, which are calculated by the time to peak (TTP) washout ratio (WR).

In head and neck tumors, perfusion CT scan findings are based on standard contrast enhancement in the helical scans, which are used to categorize morphological and oncologic characteristics. ${ }^{5,6}$

Perfusion CT can differentiate necrosis and normal tissues in large tumors. This modality visualizes reactive or metastatic lymph nodes according to the primary pattern of tumor perfusion.
By perfusion CT scan in the diagnosis and differentiation of parotid lesions; surgeons choose the best approach before surgery.

\section{Materials and Methods}

\section{Methods}

In this cross-sectional study, 35 patients who were referred to our hospital presenting with unknown solid parotid mass were candidates for parotidectomy surgery or biopsy of the lesion and were entered in a prospective study after signing consent forms.

The project was approved by the Ethics Committee. It was considered that patients do not have the constraint of receiving the contrast agents. Age and gender limitations were not considered as inclusion criteria. The number of samples was computed statistically, and it consisted of 35 admitted or non-admitted patients. According to the exclusion criteria; patients who had definite pathology detected by surgery or previous biopsy and those who did not give permission to obtain a biopsy or CT scan, as well as those who were not able to enter because of technical errors of perfusion CT scan parameters were excluded.

All patients were first examined with non-contrast CT scan sequences by an expert radiologist, and the volume of injection for perfusion CT scan was determined with the focus on the widest site of the tumor in the initial CT scan. A total of $60 \mathrm{ml}$ of non-ionic contrast agent were injected at a rate of 4 to $6 \mathrm{ml} / \mathrm{sec}$ by an injector, under the supervision of a radiologist, to perform the perfusion CT-scan. Then, within 5 to 6 seconds after the beginning of injection, the scan was taken by a 16 detectors multi-slice CT scanner, followed by $20 \mathrm{ml}$ of saline infusion with the same speed at the injection site. After performing the first stage of CT scan, the subsequent steps were continued and completed through the usual manner of cephalic and cervical CT scan (in fact, the perfusion phase of the tumor in the initial stages of injection are imaged as additional sequences in this type of CT scan and the rest of the steps are similar to conventional CT scan). No drug allergies were recorded, and total received radiation was in the range of standard. Then, for each patient, blood volume (BV), blood flow (BF), capillary permeability (CP) and TTP were calculated according to CT scan as well as the timedensity curve (TDC) diagram based on the TTP and washout ratio by standard Siemens software.

The TTP and WR parameters were used for the (TDCs) division. The TDC curve is divided into four different types based on information. Type 1 consists of the cases in which slopes of the curve are continuously rising and are not fixed on a constant peak in 60 seconds, with TTP $<30$ seconds. Type 2 has WR $>30 \%$ and TDCs with TTP $<30$ seconds. Type 3 includes cases in which the TDCs have TTP $\leq 30$ s and WR $<30 \%$; the type 4 TDCs do not have a WR; they reached the plateau phase and have a TTP $>30$ seconds.

A site $\left(3-5 \mathrm{~mm}^{2}\right)$ of the parotid tumor that had more enhancements and was relatively homogeneous was selected to measure the parameters of perfusion CT scan. When the mass was heterogeneous, the part of the tumor that had 
more enhancements was selected as the part for investigating parameters assessment or region of interest (ROI).

The criteria for measuring the parameters related to the perfusion of the CT scan of the external carotid artery were related to existing standards. The arterial diagrams and tumor charts for the TDC parameter were plotted separately, and the BV and BF entering to the tumor as well as the tissue infiltration rate of the tumor were calculated in comparison to the external carotid artery by software, after which the standard deviation (SD) was calculated separately for each parameter. In some cases that CT scans did not achieve correct results, due to technical errors; such cases were excluded from the study. Overall, one patient was excluded due to technical errors and motion artifact.

The patients were followed-up shortly after the CT scan and underwent biopsy or surgery. Patients' pathology was followed-up and collected. Five patients were excluded from the study because they chose not to have surgery.

Finally, patients were classified according to histopathology to benign or malignant tumors. In another classification, the patients were grouped in benign hypo-vascular (including PA), benign hypervascular tumors (including WT), and MTs (including mucoepidermoid carcinoma [MEC], acinic cell carcinoma [ACC], and adenocystic carcinoma $[\mathrm{AdCC}])$.

\section{Statistical Analyses}

All analyses were performed using the statistical software SPSS v. 22 (SPSS Inc., Chicago, IL, USA). Frequency and index of dispersion were calculated. A $p$-value lower than 0.05 was considered statistically significant. Normal distribution was investigated by the Shapiro-Wilk test, and nonparametric tests were used to analyze the non-normal data.

\section{Sample Size}

To evaluate the diagnostic accuracy of perfusion CT scan in the differential diagnosis of benign and malignant parotid tumors (with $90 \%$ of accuracy in similar studies), a sample size of 35 patients was calculated at $80 \%$ power and $5 \%$ standard error by the following formula:

$$
\mathrm{N}=(\mathrm{z} 1-\mathrm{a} / 2) 2(\mathrm{p})(1-\mathrm{p}) / \mathrm{d} 2
$$

A total of 35 patients were enrolled with parotid tumor diagnosis and unspecified pathology during the time period of 2017 to 2018.

\section{Results}

A total of 29 patients enrolled in the study (15 males and 14 females; mean age, $55.9 \pm 14.1$ years; range) (26-77). The lesion was located on the left side in $48.3 \%$ of cases and on the right side in $51.7 \%$. Histopathology showed that the 29 cases included 11 cases of PA (37.9\%), 8 cases of WT (27.6\%), and 10 cases of malignant lesions (34.5\%) (including 6 cases of ACC [20.7\%]. There were also three cases of AdCC [10.3\%] and one case of MEC [3.4\%]).
The mean age and all CT perfusion variables were compared among the three mentioned pathologic groups. (MTs, WTs, and PAs)

The mean age was $62 \pm 7.5$ years in WT, $52 \pm 14.2$ in PA and $55.2 \pm 17.2$ in MT [ $p=0.32]$. The mean MIP was $122.7 \pm 12.2$ in WT, while it was $80.5 \pm 19.5$ in PA, and $76.2 \pm 27.1$ in MT $(p<0.001)$; The WT mean MIP was higher than in PA and MT; the value of MT and PA are not statistically different ( - Table 1 ). the mean of all other CT perfusion variables among the three groups is mentioned in - Table 1. Mean BF, mean BV, and peak on the curve are higher in WT in comparison with the other two groups. Curve time 2 and TTP are higher in PA in comparison with MT ( - Table 1).

Considering WT and PA as benign diagnoses versus MTs, we used receiver operating characteristic (ROC) analyses for differentiating malignant from benign pathologies. The area under the ROC curves (AUC) was calculated (-Fig. 1). Among all variables, the highest statistically significant AUCs were for the standard deviation of MIP (AUC $=0.8$ ), curve peak $($ AUC $=0.81)$ and a new variable made by multiplication of MIP mean and MIP standard deviation (-Table 2 ).

Based on the ROC curve (-Fig. 1), we have calculated diagnostic indices of some of the best cutoff points for these three variables with their 95\% confidence intervals (CIs) (-Table 3 ).

According to the results of the analysis of variance (ANOVA), MIP mean, BF, BV, and curve peak indicate that the differences among WT versus the other pathologies (PAs and MTs) are statistically significant. So, the ROC analyses were used to differentiate WT from the two other diagnoses [-Fig. 2]. In this regard, all of the variables showed excellent efficiency for differentiating WTs (all of AUCs were greater than 0.93). But the best variable was MIP mean, which showed an AUC of $0.99(p<0.001)$ [ $~-$ Fig. 2]. So, this variable was selected for differentiating WTs. The selected cutoff points and their diagnostic indices for this variable have been mentioned in - Table 4.

Based on the ROC analysis for WT, a cutoff point $\geq 116$ for MIP mean ( - Fig. 3), there is a positive predictive value of 100 for determining the WT. So, we set aside the lesions with MIP mean $\geq 116$ as WT and repeat our analysis for differentiating malignant from benign lesions on the rest of the patients, considering the study variables. In this situation, we omitted 6 patients with MIP mean $\geq 116$; thus, we had 23 patients, among whom 10 had malignant and 13 had benign tumors (11 were PA and two were WT). Again, we used the ROC analysis for differentiating malignant from benign tumors. In this situation, the best AUCs (their $p$-values were statistically significant) were shown for MIP SD, and the best MIP means for MIP SD, TTP, and curve time 2. Their ROC analysis findings are shown in - Table 5 .

Based on the ROC curves of these four variables, we selected the best cutoff points for differentiating malignant from benign lesions. The results have been mentioned in -Table 6 .

Considering the curve types, we had 11 descending curves (37.9\%), among which three were malignant (27.3\%); 16 of the curves were the plateau (55.2\%), among which 7 were malignant (43.8\%); and 2 were ascending (6.9\%), both of 
Table 1 Comparison of all computed tomography perfusion variables among three main pathological diagnoses of Warthin's tumor, pleomorphic adenoma, and malignant tumor

\begin{tabular}{|c|c|c|c|c|c|}
\hline & & & Mean \pm SD & $P$-value & Details of comparison between groups \\
\hline \multirow[t]{6}{*}{ MIP } & \multirow[t]{3}{*}{ Mean } & WT & $122.7 \pm 12.2$ & \multirow[t]{3}{*}{$<0.001$} & \multirow[t]{3}{*}{$(\mathrm{PA}=\mathrm{MT})<\mathrm{WT}$} \\
\hline & & $\mathrm{PA}$ & $80.5 \pm 19.5$ & & \\
\hline & & MT & $76.2 \pm 27.1$ & & \\
\hline & \multirow[t]{3}{*}{ SD } & WT & $6.2 \pm 2.2$ & \multirow[t]{3}{*}{0.053} & \multirow[t]{3}{*}{$\mathrm{WT}=\mathrm{PA}=\mathrm{MT}$} \\
\hline & & PA & $5.9 \pm 2.3$ & & \\
\hline & & MT & $3.9 \pm 1.9$ & & \\
\hline \multirow[t]{6}{*}{$\mathrm{BF}$} & \multirow[t]{3}{*}{ Mean } & WT & $93.2 \pm 35.5$ & \multirow[t]{3}{*}{0.001} & \multirow[t]{3}{*}{$(\mathrm{PA}=\mathrm{M})<\mathrm{WT}$} \\
\hline & & $\mathrm{PA}$ & $38.9 \pm 21$ & & \\
\hline & & MT & $43.1 \pm 32.3$ & & \\
\hline & \multirow[t]{3}{*}{ SD } & WT & $4.9 \pm 2.6$ & \multirow[t]{3}{*}{0.95} & \multirow[t]{3}{*}{$\mathrm{WT}=\mathrm{PA}=\mathrm{MT}$} \\
\hline & & PA & $4.4 \pm 3.9$ & & \\
\hline & & MT & $4.5 \pm 4.7$ & & \\
\hline \multirow[t]{6}{*}{ BV } & \multirow[t]{3}{*}{ Mean } & WT & $28.1 \pm 8.5$ & \multirow[t]{3}{*}{$<0.001$} & \multirow[t]{3}{*}{$(\mathrm{PA}=\mathrm{MT})<\mathrm{WT}$} \\
\hline & & $\mathrm{PA}$ & $8.1 \pm 5.2$ & & \\
\hline & & MT & $8.9 \pm 6.7$ & & \\
\hline & \multirow[t]{3}{*}{ SD } & WT & $2.7 \pm 2.3$ & \multirow[t]{3}{*}{0.1} & \multirow[t]{3}{*}{$\mathrm{WT}=\mathrm{PA}=\mathrm{MT}$} \\
\hline & & PA & $0.9 \pm 0.7$ & & \\
\hline & & MT & $1.2 \pm 2.3$ & & \\
\hline \multirow[t]{6}{*}{ PMB } & \multirow[t]{3}{*}{ Mean } & WT & $16.9 \pm 11.6$ & \multirow[t]{3}{*}{0.08} & \multirow[t]{3}{*}{$\mathrm{WT}=\mathrm{PA}=\mathrm{MT}$} \\
\hline & & PA & $27.9 \pm 12.2$ & & \\
\hline & & MT & $22.2 \pm 5.4$ & & \\
\hline & \multirow[t]{3}{*}{ SD } & WT & $2.3 \pm 1.7$ & \multirow[t]{3}{*}{0.99} & \multirow[t]{3}{*}{$\mathrm{WT}=\mathrm{PA}=\mathrm{MT}$} \\
\hline & & PA & $2.2 \pm 2$ & & \\
\hline & & MT & $2.3 \pm 3.1$ & & \\
\hline TTP & Mean & WT & $29.4 \pm 5.6$ & 0.016 & $\mathrm{WT}=\mathrm{MT}, \mathrm{WT}=\mathrm{PA}, \mathrm{MT}<\mathrm{PA}$ \\
\hline & & PA & $37.7 \pm 11.9$ & & \\
\hline & & MT & $26.5 \pm 5.3$ & & \\
\hline Curve Time 1 & Mean & WT & $13.1 \pm 4.6$ & 0.28 & $\mathrm{WT}=\mathrm{PA}=\mathrm{MT}$ \\
\hline & & PA & $12.3 \pm 4.1$ & & \\
\hline & & MT & $10.8 \pm 3.3$ & & \\
\hline Curve Time 2 & Mean & WT & $28.8 \pm 5.2$ & 0.013 & $\mathrm{WT}=\mathrm{MT}, \mathrm{WT}=\mathrm{PA}, \mathrm{MT}<\mathrm{PA}$ \\
\hline & & PA & $37.7 \pm 11.9$ & & \\
\hline & & MT & $26.5 \pm 5.3$ & & \\
\hline Curve Peak & Mean & WT & $72.1 \pm 12.2$ & $<0.001$ & $(\mathrm{PA}=\mathrm{MT})<\mathrm{WT}$ \\
\hline & & $\mathrm{PA}$ & $35.9 \pm 17.5$ & & \\
\hline & & $\mathrm{MT}$ & $27.2 \pm 6.2$ & & \\
\hline
\end{tabular}

Abbreviations: BF, blood flow; BV, blood volume; MIP, maximum intensity projection; MT, malignant tumor; PA, pleomorphic adenoma; PMB, permeability; SD, standard deviation; TTP, time to peak; WT, Warthin's tumor.

which were benign ( $p=0.49)$. Combining different groups of curve types to constitute a dichotomous variable and analysis of them versus malignancy, did not show a significant result for this variable in differentiating malignant from benign lesions. When we consider descending patterns as a marker for WT (combining plateau and ascending together), we showed a statistically significant result ( $p=0.001)$, and the sensitivity and specificity were $88 \%$ and $81 \%$, respectively. In addition, when we considered the plateau or ascending curves as the marker for PA lesions, we encounter a statistically significant result $(p=0.019)$, and the sensitivity and specificity of curve type for differentiating PA lesions were $91 \%$ and $56 \%$, 


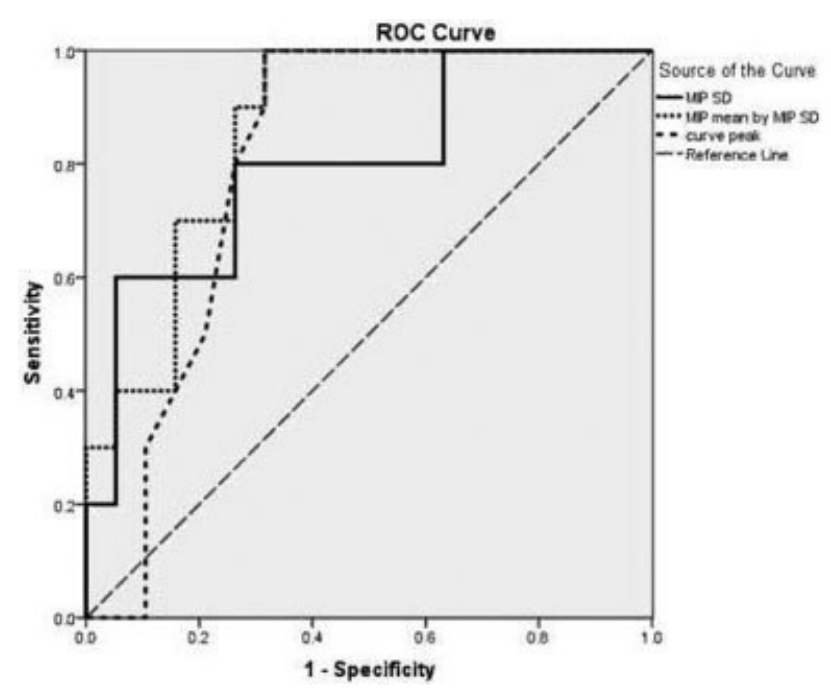

Fig. 1 Receiver operating characteristic curves of maximum intensity projection (MIP) standard deviation (SD), MIP mean by MIP SD, and curve peak for differentiating malignant from benign lesions.

respectively. The details for these analyses and the diagnostic indices have been mentioned in - Table 7.

\section{Discussion}

The parotid gland is the largest salivary gland in the human body. Differentiating benign from malignant lesions of the parotid is very important in certain circumstances: 1) when surgery is impossible for the patient, due to physical conditions, aging, or underlying ailments, 2) When the spread of the tumor is unclear, 3) Investigation of the surgical approach for lesions that extended into the parapharyngeal space, 4) In cases of malignant tumors and when the facial nerve should be removed. 5) In cases of large or constant tumors, and 6) When there is suspicion of skin involvement or lymphadenopathy, and when preoperative planning for neck dissection is needed. ${ }^{7}$

In this study, the most common parotid tumor was PA and then, WT, in contrast to the malignant lesions, which had various histopathological parameters that coincided with the findings of Knopf. ${ }^{8}$

The success rate of perfusion CT scan was $97.1 \%$, which was consistent with the study of Dong. ${ }^{9}$ A parotid perfusion CT scan is an easy way to examine parotid lesions because it is not affected by motion artifacts. Dentures and also the larynx movements in the low position of some parotid masses can cause artifacts. Patients need to remove dentures and avoid swallowing during the perfusion CT scan. ${ }^{9}$ There was a significant statistical difference in the gender distribution of malignant and benign tumors, with $p$-value $<0.01$, and malignant tumors were more prevalent in females than in males. Most of the benign tumors were seen in males, while this parameter has not been measured in other studies. There was no significant correlation between the benign and malignant parotid tumors with age $(p$-value $=0.36)$.

When we evaluated the TDCs, we found that patients with WT had a high rate of a rapid increase in the WR pattern that was similar to the findings of Dong et al. ${ }^{9}$ Ascending TDCs and plateau type 4 were more common in PA. In this study, TDC type 1 and type 4 were more common in hypovascular benign masses and curve type 2 in hypervascular benign masses, and most of type 4 and type 3 were seen in the malignant group. According to the statistical analysis, this correlation was significant. According to the data from the Jie Wang study, TDCs patterns had a significant correlation among the three groups. Also, BV, BF, and MIP in benign WT were significantly higher than pleomorphic adenoma,

Table 2 Areas under the curve of different variables in receiver operating characteristics analyses for differentiating malignant from benign pathologies

\begin{tabular}{|l|l|l|l|l|l|}
\hline Variable & Area & Standard & P-value & \multicolumn{2}{l|}{ 95\% Confidence Interval } \\
\cline { 5 - 6 } & & Error (SE) & & Lower bound & Upper bound \\
\hline MIP mean & 0.71 & 0.1 & 0.066 & 0.52 & 0.90 \\
\hline MIP SD & 0.80 & 0.09 & 0.009 & 0.62 & 0.98 \\
\hline MIP mean by MIP SD & 0.86 & 0.07 & 0.002 & 0.73 & 0.99 \\
\hline BF mean & 0.68 & 0.11 & 0.119 & 0.47 & 0.89 \\
\hline BF SD & 0.54 & 0.13 & 0.714 & 0.30 & 0.787 \\
\hline BV mean & 0.66 & 0.11 & 0.155 & 0.46 & 0.87 \\
\hline BV SD & 0.72 & 0.11 & 0.054 & 0.50 & 0.94 \\
\hline PMB mean & 0.50 & 0.11 & 0.963 & 0.29 & 0.71 \\
\hline PMB SD & 0.56 & 0.12 & 0.630 & 0.32 & 0.79 \\
\hline TTP & 0.76 & 0.09 & 0.026 & 0.58 & 0.93 \\
\hline Curve time 1 & 0.64 & 0.11 & 0.233 & 0.42 & 0.85 \\
\hline Curve time 2 & 0.75 & 0.09 & 0.033 & 0.56 & 0.93 \\
\hline Curve peak & 0.81 & 0.08 & 0.008 & 0.64 & 0.97 \\
\hline
\end{tabular}

Abbreviations: BF, blood flow; BV, blood volume; MIP, maximum intensity projection; PMB, permeability; SD, standard deviation; TTP, time to peak. 
Table 3 Selected cutoff points and their diagnostic indices for differentiating malignant from benign lesions for the best variables

\begin{tabular}{|c|c|c|c|c|c|c|c|c|}
\hline $\begin{array}{l}\text { Variable and its } \\
\text { Cutoff point }\end{array}$ & $\begin{array}{l}\text { TP, FN, } \\
\text { TN, } \\
\text { FP }\end{array}$ & $\begin{array}{l}\text { Sen \% } \\
(95 \% \mathrm{Cl})\end{array}$ & $\begin{array}{l}\text { Spec \% } \\
(95 \% \mathrm{Cl})\end{array}$ & $\begin{array}{l}\text { PPV \% } \\
(95 \% \mathrm{Cl})\end{array}$ & $\begin{array}{l}\text { NPV \% } \\
(95 \% \mathrm{Cl})\end{array}$ & $\begin{array}{l}\text { PLR } \\
(95 \% \mathrm{Cl})\end{array}$ & $\begin{array}{l}\text { NLR } \\
(95 \% \mathrm{CI})\end{array}$ & $\begin{array}{l}\text { Accuracy \% } \\
(95 \% \text { Cl) }\end{array}$ \\
\hline $\begin{array}{l}\text { MIP SD by MIP } \\
\text { mean } \leq 497 \\
\text { curve peak } \leq 37\end{array}$ & $\begin{array}{l}10, \\
0, \\
13 \\
6\end{array}$ & $\begin{array}{l}100 \\
(69-100)\end{array}$ & $\begin{array}{l}68 \\
(43-87)\end{array}$ & $\begin{array}{l}63 \\
(35-85)\end{array}$ & $\begin{array}{l}100 \\
(75-100)\end{array}$ & $\begin{array}{l}3.2 \\
(1.6-6.1)\end{array}$ & - & $\begin{array}{l}79 \\
(60-92)\end{array}$ \\
\hline $\begin{array}{l}\text { MIP SD by MIP } \\
\text { mean } \leq 400\end{array}$ & $\begin{array}{l}9 \\
1, \\
14 \\
5\end{array}$ & $\begin{array}{l}90 \\
(55-99)\end{array}$ & $\begin{array}{l}74 \\
(49-91)\end{array}$ & $\begin{array}{l}64 \\
(35-87)\end{array}$ & $\begin{array}{l}93 \\
(68-99)\end{array}$ & $\begin{array}{l}3.4 \\
(1.6-7.5)\end{array}$ & $\begin{array}{l}7.4 \\
(1.1-48.2)\end{array}$ & $\begin{array}{l}79 \\
(60-92)\end{array}$ \\
\hline $\begin{array}{l}\text { MIP SD } \leq 4.5 \\
\text { curve peak } \leq 32\end{array}$ & $\begin{array}{l}8, \\
2, \\
14, \\
5\end{array}$ & $\begin{array}{l}80 \\
(44-97)\end{array}$ & $\begin{array}{l}74 \\
(49-91)\end{array}$ & $\begin{array}{l}62 \\
(32-86)\end{array}$ & $\begin{array}{l}88 \\
(62-98)\end{array}$ & $\begin{array}{l}3 \\
(1.3-6.9)\end{array}$ & $\begin{array}{l}3.7 \\
(1-13.1)\end{array}$ & $\begin{array}{l}76 \\
(56-90)\end{array}$ \\
\hline $\mathrm{MIP} S \mathrm{SD} \leq 3.3$ & $\begin{array}{l}6 \\
4, \\
18 \\
1\end{array}$ & $\begin{array}{l}60 \\
(26-88)\end{array}$ & $\begin{array}{l}95 \\
(74-99)\end{array}$ & $\begin{array}{l}86 \\
(42-99)\end{array}$ & $\begin{array}{l}82 \\
(60-95)\end{array}$ & $\begin{array}{l}11.4 \\
(1.6-82)\end{array}$ & $\begin{array}{l}2.4 \\
(1.1-5.1)\end{array}$ & $\begin{array}{l}83 \\
(64-94)\end{array}$ \\
\hline $\begin{array}{l}\text { MIP SD by MIP } \\
\text { mean } \leq 175\end{array}$ & $\begin{array}{l}3, \\
7, \\
19 \\
0\end{array}$ & $\begin{array}{l}30 \\
(7-65)\end{array}$ & $\begin{array}{l}100 \\
(82-100)\end{array}$ & $\begin{array}{l}100 \\
(29-100)\end{array}$ & $\begin{array}{l}73 \\
(52-88)\end{array}$ & - & $\begin{array}{l}1.4 \\
(0.95-2.14)\end{array}$ & $\begin{array}{l}76 \\
(56-90)\end{array}$ \\
\hline
\end{tabular}

Abbreviations: $\mathrm{Cl}$, confidence interval; MIP, maximum intensity projection; SD, standard deviation; TP, true negative; FN, false negative; TN, true negative; FP, false positive; Sen, sensitivity; Spec, specificity; PPV, positive predictive value; NPV, negative predictive value; PLR, positive likelihood ratio; NLR, negative likelihood ratio.

which is the same result found by Wang in his study. ${ }^{10}$ Type2 TDC helps to differentiate between the benign hypervascular and malignant hypovascular masses. The presence of a rich capillary network and a large number of blood vessels with weak walls in this group of masses, especially in the cases of WT, can justify this pattern. Most of the malignant masses had curve type 3 , as well as most hypovascular masses of curve type 4 ; this is probably due to lower blood flow in benign masses and intact vascular walls in these masses. Therefore, different types of TDC charts can reflect microcirculation in parotid masses and help distinguish

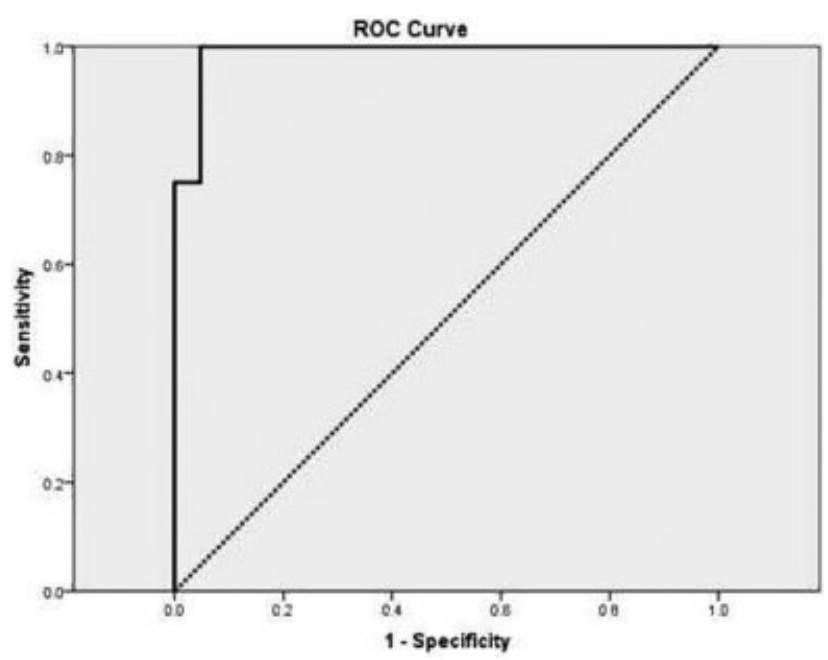

Fig. 2 Receiver operating characteristic curve of maximum intensity projection (MIP) mean for differentiating Warthin's tumor (WT) from two other pathologies. between different types of tumors. ${ }^{11}$ Higher blood flow and volume (BF and BV) in benign tumors are significant, which may help to differentiate benign and malignant salivary gland tumors by CT perfusion; because malignant lesions have a copious amount of areas of necrosis. Warthin's tumor and PA have higher BF and BV and lower BF and BV than malignant lesions, respectively. ${ }^{12}$

This modality can differentiate benign and malignant tumors by mean transit time (MTT); in the study by Razek et al, when MTT $\leq 3.5$, the lesion was considered malignant, and MTT $\geq 5.5$ malignancy is impossible. The cellularitystromal grade is higher in benign lesions, and microfoci of necrosis are more common in the malignant lesion; hence, increased $\mathrm{BF}$ and $\mathrm{BV}$ are more common in the tumoral than in normal parotid lesions. These two parameters are significantly higher in benign than in malignant parotid lesions. Parotid tumors also show lower MTT and elevated PS when compared with normal tissues. ${ }^{13}$ There was no significant difference in the parameters of perfusion CT scan, including $\mathrm{BF}$ and $\mathrm{BV}$ between benign and malignant parotid tumors, in a study by Bisdas $\mathrm{S}$ et al, which is due to different stromal cellularity in benign and malignant lesions. ${ }^{7}$ Perfusion CT scan is not favorable in the differentiation between some benign and malignant parotid tumors when the benign group has a wide variety of histopathological features, and some benign masses such as WTs have high BF and BV. ${ }^{9}$ Therefore, in this study, the focus was on the differentiation of tumors in terms of vascularity, benign and malignant lesions; hence, the samples were divided into three groups; PA (benign hypovascular), WT (benign hypervascular), and malignant lesions. The difference between PA 
Table 4 Selected cutoff points and their diagnostic indices for differentiating Warthin's tumor from malignant lesions and pleomorphic adenoma based on maximum intensity projection mean

\begin{tabular}{|c|c|c|c|c|c|c|c|c|}
\hline $\begin{array}{l}\text { Variable and its } \\
\text { cutoff point }\end{array}$ & $\begin{array}{l}\text { TP, FN, TN, } \\
\text { FP }\end{array}$ & $\begin{array}{l}\text { Sen \% } \\
{[95 \% \mathrm{CI}]}\end{array}$ & $\begin{array}{l}\text { Spec \% } \\
{[95 \% \mathrm{Cl}]}\end{array}$ & $\begin{array}{l}\text { PPV \% } \\
{[95 \% \mathrm{Cl}]}\end{array}$ & $\begin{array}{l}\text { NPV \% } \\
{[95 \% \mathrm{Cl}]}\end{array}$ & $\begin{array}{l}\text { PLR } \\
{[95 \% \mathrm{Cl}]}\end{array}$ & $\begin{array}{l}\text { NLR } \\
{[95 \% \mathrm{Cl}]}\end{array}$ & $\begin{array}{l}\text { Accuracy \% } \\
{[95 \% \mathrm{Cl}]}\end{array}$ \\
\hline MIP mean $\geq 101.5$ & $\begin{array}{l}8, \\
0, \\
20, \\
1\end{array}$ & $\begin{array}{l}100 \\
(63-100)\end{array}$ & $\begin{array}{l}95 \\
(76-99)\end{array}$ & $\begin{array}{l}89 \\
(52-9)\end{array}$ & $\begin{array}{l}100 \\
(83-100)\end{array}$ & $\begin{array}{l}21 \\
(3.1-142.2)\end{array}$ & - & $\begin{array}{l}79 \\
(82-99)\end{array}$ \\
\hline MIP mean $\geq 116$ & $\begin{array}{l}9, \\
1, \\
14, \\
5\end{array}$ & $\begin{array}{l}75 \\
(35-97)\end{array}$ & $\begin{array}{l}100 \\
(84-100)\end{array}$ & $\begin{array}{l}100 \\
(54-100)\end{array}$ & $\begin{array}{l}91 \\
(72-99)\end{array}$ & -- & $\begin{array}{l}4 \\
(1.2-13.3)\end{array}$ & $\begin{array}{l}93 \\
(77-99)\end{array}$ \\
\hline
\end{tabular}

Abbreviations: $\mathrm{Cl}$, confidence interval; MIP, maximum intensity projection; TP, true negative; FN, false negative; TN, true negative; FP, false positive; Sen, sensitivity; Spec, specificity; PPV, positive predictive value; NPV, negative predictive value; PLR, positive likelihood ratio; NLR, negative likelihood ratio.

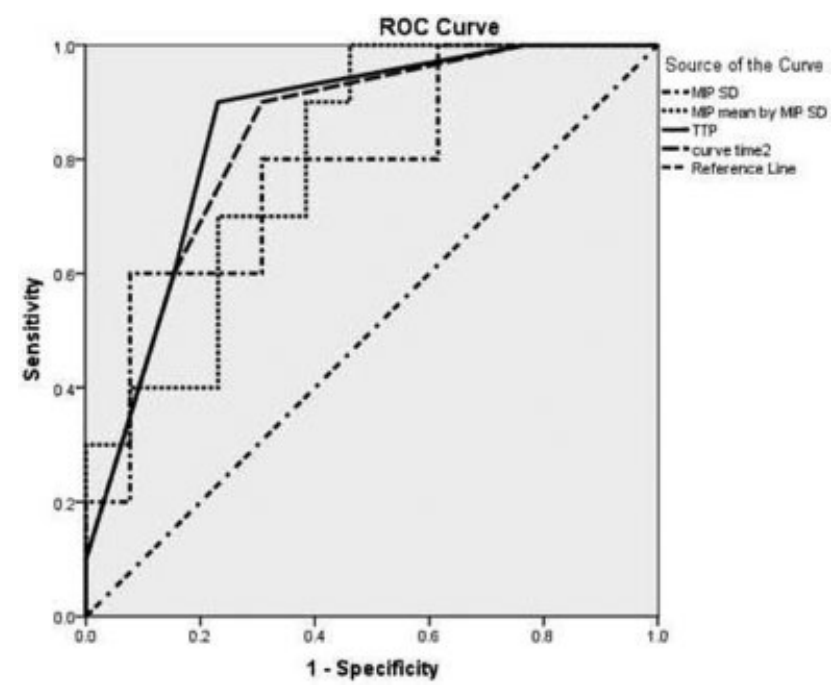

Fig. 3 Receiver operating characteristic curve of maximum intensity projection (MIP) standard deviation (SD), MIP mean by MIP SD, time to peak (TTP), and curve time 2 for differentiating malignant lesions after deleting lesions with MIP mean $\geq 116$.

and WT masses was significant in terms of BF, BV, and MIP in all parameters ( $p$-value $\geq 0.001$ ). Observing patients with WT is acceptable with attention to the characteristics of this type of tumor, but PA may become malignant. ${ }^{14}$ Perhaps the perfusion CT scan can be used to select the type of treatment in benign parotid masses. The difference between WTs and MTs by MIP, BV, and BF was significant ( $p$-value $\geq 0.001$ ), which is similar to the results of the study by Wang. ${ }^{10}$ The overall mean of BV, BF, and MIP for MTs was higher than that for PA but did not have a significant correlation with the statistical analysis. The presence of multiple areas of necrosis in the malignant lesions can be a factor to reduce the perfusion CT parameters. ${ }^{10}$ Therefore, MIP, BV, and BF, which reflect the angiogenesis of tumors that can partly be distinguished from the three groups. In this study, the highest mean BF and BV were seen in WTs. There was no significant difference between benign and MTs in terms of permeability. In the study of Dong et al, BV, $\mathrm{BF}$, and PS in PAs were lower than in MTs; the opposite was true in relation to basal cell adenoma, and WT had higher BV and BF than MTs; tumor vascular permeability in the basal adenoma was also higher than in MTs. ${ }^{9}$ It seems that with regard to the high diversity of benign parotid tumors and different patterns of perfusion CT scan parameters, this modality is not appropriate as a comparative method for benign and malignant parotid tumors. In terms of capillary permeability, permeability surface (PS), and TTP, there was no statistically significant difference among the benign and malignant groups, the WT group, and the PA group. The PS factor had no statistically significant difference among WTs, PAs, and MTs, which was also similar to the results found in the study by Bisdas. ${ }^{7}$ However, in the study by Wang et al, ${ }^{15}$ there was a positive correlation between benign and malignant tumors in terms of PMB, while in the study by Bisdas et $\mathrm{al}^{7}{ }^{7}$ there was no clear association that could be justified in view of the possibility of heterogeneity in the ROI

Table 5 Areas under the curve of different variables in receiver operating characteristics analyses for differentiating malignant from benign pathologies after deleting with maximum intensity projection $\geq 116$

\begin{tabular}{|l|l|l|l|l|l|}
\hline Variable & Area & Standard & \multirow{2}{*}{$\begin{array}{l}\text { P-value } \\
\text { error (SE) }\end{array}$} & & \multicolumn{2}{|l|}{ 95\% Confidence Interval } \\
\cline { 5 - 6 } & & & & Lower bound & Upper bound \\
\hline MIP SD & 0.79 & 0.1 & 0.022 & 0.59 & 0.98 \\
\hline MIP mean by MIP SD & 0.80 & 0.09 & 0.016 & 0.62 & 0.98 \\
\hline TTP & 0.85 & 0.08 & 0.004 & 0.67 & 1 \\
\hline Curve time 2 & 0.84 & 0.08 & 0.006 & 0.67 & 1 \\
\hline
\end{tabular}

Abbreviations: MIP, maximum intensity projection; SD, standard deviation; TTP, time to peak. 
Table 6 Selected cutoff points and their diagnostic indices for differentiating malignant tumors from other benign lesions after deleting lesions with maximum intensity projection mean equal or greater than 116

\begin{tabular}{|c|c|c|c|c|c|c|c|c|}
\hline $\begin{array}{l}\text { Variable and its } \\
\text { cutoff point }\end{array}$ & $\begin{array}{l}\text { TP, FN, TN, } \\
\text { FP }\end{array}$ & $\begin{array}{l}\text { Sen \% } \\
{[95 \% \mathrm{Cl}]}\end{array}$ & $\begin{array}{l}\text { Spec \% } \\
{[95 \% \mathrm{Cl}]}\end{array}$ & $\begin{array}{l}\text { PPV \% } \\
{[95 \% \mathrm{Cl}]}\end{array}$ & $\begin{array}{l}\text { NPV \% } \\
{[95 \% \mathrm{Cl}]}\end{array}$ & $\begin{array}{l}\text { PLR } \\
{[95 \% \mathrm{Cl}]}\end{array}$ & $\begin{array}{l}\text { NLR } \\
{[95 \% \mathrm{Cl}]}\end{array}$ & $\begin{array}{l}\text { Accuracy \% } \\
{[95 \% \mathrm{Cl}]}\end{array}$ \\
\hline $\begin{array}{l}\text { MIP mean by } \\
\text { MIP SD } \leq 500\end{array}$ & $\begin{array}{l}10, \\
0, \\
7, \\
6\end{array}$ & $\begin{array}{l}100 \\
(69-100)\end{array}$ & $\begin{array}{l}54 \\
(25-81)\end{array}$ & $\begin{array}{l}63 \\
(35-85)\end{array}$ & $\begin{array}{l}100 \\
(59-100)\end{array}$ & $\begin{array}{l}2.2 \\
(1.2-3.9)\end{array}$ & - & $\begin{array}{l}74 \\
(52-90)\end{array}$ \\
\hline $\mathrm{TTP} \leq 30$ & $\begin{array}{l}9, \\
1, \\
10, \\
3\end{array}$ & $\begin{array}{l}90 \\
(56-99)\end{array}$ & $\begin{array}{l}77 \\
(46-95)\end{array}$ & $\begin{array}{l}75 \\
(43-95)\end{array}$ & $\begin{array}{l}91 \\
(59-99)\end{array}$ & $\begin{array}{l}3.9 \\
(1.4-10.7)\end{array}$ & $\begin{array}{l}7.7 \\
(1.2-50.6)\end{array}$ & $\begin{array}{l}83 \\
(61-95)\end{array}$ \\
\hline $\mathrm{MIP} S \mathrm{SD} \leq 3.2$ & $\begin{array}{l}6, \\
4, \\
12, \\
1\end{array}$ & $\begin{array}{l}60 \\
(26-88)\end{array}$ & $\begin{array}{l}92 \\
(64-99)\end{array}$ & $\begin{array}{l}86 \\
(42-99)\end{array}$ & $\begin{array}{l}75 \\
(48-93)\end{array}$ & $\begin{array}{l}7.8 \\
(1.1-54.8)\end{array}$ & $\begin{array}{l}2.3 \\
(1.1-5)\end{array}$ & $\begin{array}{l}78 \\
(56-93)\end{array}$ \\
\hline $\begin{array}{l}\text { MIP mean by } \\
\text { MIP SD } \leq 170\end{array}$ & $\begin{array}{l}3, \\
7, \\
13, \\
0\end{array}$ & $\begin{array}{l}30 \\
(7-65)\end{array}$ & $\begin{array}{l}100 \\
(75-100)\end{array}$ & $\begin{array}{l}100 \\
(29-100)\end{array}$ & $\begin{array}{l}65 \\
(41-85)\end{array}$ & - & $\begin{array}{l}1.4 \\
(0.95-2.1)\end{array}$ & $\begin{array}{l}70 \\
(47-87)\end{array}$ \\
\hline
\end{tabular}

Abbreviations: $\mathrm{Cl}$, confidence interval; MIP, maximum intensity projection; MT, malignant tumor; SD, standard deviation; TP, true negative; FN, false negative; TN, true negative; FP, false positive; Sen, sensitivity; Spec, specificity; PPV, positive predictive value; NPV, negative predictive value; PLR, positive likelihood ratio; NLR, negative likelihood ratio.

Table 7 Diagnostic indices of curve type for differentiating Warthin's tumor and pleomorphic adenoma

\begin{tabular}{|c|c|c|c|c|c|c|c|c|}
\hline Variable & $\begin{array}{l}\text { TP, FN, TN, } \\
\text { FP }\end{array}$ & $\begin{array}{l}\text { Sen \% } \\
(95 \% \mathrm{Cl})\end{array}$ & $\begin{array}{l}\text { Spec \% } \\
(95 \% \mathrm{Cl})\end{array}$ & $\begin{array}{l}\text { PPV \% } \\
(95 \% \mathrm{Cl})\end{array}$ & $\begin{array}{l}\text { NPV \% } \\
(95 \% \text { Cl) }\end{array}$ & $\begin{array}{l}\text { PLR } \\
\text { (95\% Cl) }\end{array}$ & $\begin{array}{l}\text { NLR } \\
\text { (95\% Cl) }\end{array}$ & $\begin{array}{l}\text { Accuracy \% } \\
(95 \% \mathrm{Cl})\end{array}$ \\
\hline $\begin{array}{l}\text { Curve type: } \\
\text { descending type as a } \\
\text { marker for WT }\end{array}$ & $\begin{array}{l}7, \\
1, \\
17, \\
4\end{array}$ & $\begin{array}{l}88 \\
(47-99)\end{array}$ & $\begin{array}{l}81 \\
(58-95)\end{array}$ & $\begin{array}{l}64 \\
(31-89)\end{array}$ & $\begin{array}{l}94 \\
(73-99)\end{array}$ & $\begin{array}{l}2.2 \\
(1.2-3.9)\end{array}$ & $\begin{array}{l}4.6 \\
(1.8-11.5)\end{array}$ & $\begin{array}{l}83 \\
(64-94)\end{array}$ \\
\hline $\begin{array}{l}\text { Curve type: } \\
\text { plateau or ascending } \\
\text { types as PA }\end{array}$ & $\begin{array}{l}10, \\
1, \\
10, \\
8\end{array}$ & $\begin{array}{l}91 \\
(59-99)\end{array}$ & $\begin{array}{l}56 \\
(31-78)\end{array}$ & $\begin{array}{l}56 \\
(31-78)\end{array}$ & $\begin{array}{l}91 \\
(59-99)\end{array}$ & $\begin{array}{l}2 \\
(1.2-3.5)\end{array}$ & $\begin{array}{l}6.1 \\
(0.9-41.4)\end{array}$ & $\begin{array}{l}69 \\
(49-85)\end{array}$ \\
\hline
\end{tabular}

Abbreviations: $\mathrm{Cl}$, confidence interval; PA, pleomorphic adenoma; WT, Warthin's tumor; TP, true negative; FN, false negative; TN, true negative; FP, false positive; Sen, sensitivity; Spec, specificity; PPV, positive predictive value; NPV, negative predictive value; PLR, positive likelihood ratio; NLR, negative likelihood ratio.

region. $^{7}$ To minimize this pitfall, we tried to select a solid region of the tumor and the most homogeneous ROI to avoid selecting necrotic regions; meanwhile, users may prefer to choose different shape and size of a tumor ROI for the definition, although Tawfik et al showed both methods (single section with largest tumor dimensions or average of multiple sections) are acceptable. ${ }^{16}$ However, TTP showed a statistically significant difference between PAs and MTs ( $p$-value $=0.016$ ). Peak time in the PA was higher than in MTs. Considering that the TTP factor is dependent on the cardiovascular system, it is not a suitable factor for the analysis of perfusion CT scans based on previous studies. ${ }^{4}$ In a study by Tawfik et al ${ }^{17}$, they strongly showed that for obtaining CT perfusion (CP) parameters of head and neck tumors, using the internal carotid artery (ICA), external carotid artery (ECA), and contralateral ICA are totally accepted; although they suggested the use of ICA instead of ECA to standardize and simplify the postprocessing; if the ipsilateral ICA is affected by lesions, contralateral
ICA is the choice. It seems that $\mathrm{BF}$ and $\mathrm{BV}$ are more reliable factors than PMB and TTP for comparing different types of parotid tumors due to the presence of controversies in different studies.

The TDC-peak curve in this study was compared among different groups of patients, on the contrary to other studies, and according to this parameter, a statistically significant difference was found between benign and malignant lesions ( $p$-value $=0.008)$. There was also a significant difference between the WT and malignant masses $(p=0.001)$. The mean of this parameter for hypovascular benign lesions was 35.9, which may be due to the time needed for benign masses to increase toward the peak, as well as higher permeability in lining tissues of the malignant lesions, which would not allow higher elevation toward the peak.

Other diffusion imaging techniques, such as monoexponential, biexponential intravoxel incoherent motion (microvascularity), diffusion kurtosis imaging (intravoxel heterogeneity), diffusion tensor imaging (anisotropy), and 
diffusion tensor tractography are available to evaluate salivary glands by a large number of parameters; these MRI methods may differentiate malignant from benign lesions and have a role in the assessment of patients after surgery, radiotherapy, and iodine-induced sialadenitis as well as in early diagnosis and staging of Sjögren syndrome. ${ }^{12}$ Generally, due to the availability of CT scan, as well as the statistical correlations established among different types of parotid lesions, the average price for a CT scan in comparison with MRI, perfusion CT scan may be considered as a diagnostic modality to evaluate the remaining tumor, cervical metastasis, and treatment response of medically compromised patients.

\section{Study Limitations}

First, the overall dose of radiation that scans the patient in perfusion CT is greater than that in conventional CT scans, which is possibly reduced to lowest doses by dual-energy CT scanners and reconstruction methods that were not higher than standard doses. Secondly, a range of $\sim 3$ to $5 \mathrm{~mm}^{2}$ was used to evaluate the parameters, due to the use of a 16-slice CT scanner. Parotid glands are superficial; the largest tumor diameters were used for evaluation. Third, the classification of malignant tumors and the study of the characteristics of each group were not possible, due to the small number of samples. Generally, perfusion CT scan results can help in identifying different types of parotid lesions. However, further investigation is needed with more samples to stabilize the available information.

\section{Conclusion}

According to this study, perfusion CT scan parameters can differentiate between WT, PA, and MTs. As a result of the modified imaging techniques in recent years, attention has been paid to the strategies used to diagnose parotid masses. ${ }^{18}$ Based on various types of articles, a perfusion CT scan can be used to differentiate benign from malignant parotid masses. $^{4,7,9}$ Perfusion CT scan is a functional imaging technique that is used to determine the tumor vascularity. Tumors with higher BF are more sensitive to radiotherapy, and they also have a higher risk of damage to cells caused by free radicals. ${ }^{14}$ Additionally, perfusion CT can be used to evaluate response to radiotherapy. ${ }^{14,19,20}$ Blood flow and PMB parameters are directly related to local tumor control. ${ }^{14}$ According to various studies, perfusion CT scan parameters can also be used to predict tumor recurrence following surgery and radiotherapy. ${ }^{14}$ Computed tomography perfusion parameters could be used to select a patient for surgery and radiotherapy because unfavorable basic characteristics of lesions are usually associated with aggressive phenotypes. Computed tomography perfusion is based on angiogenic activities, which may be useful to differentiate between non-neoplastic and neoplastic tissues. Therefore, CT perfusion parameters can be used to differentiate between reactive lymph nodes and nodal metastases and also figuring out cancer stage. $^{21,22}$ Computed tomography perfusion can dis- tinguish normal tissues from necrotic, fibrotic, and tumoral tissues. Therefore, according to studies, it seems that the use of this modality in head and neck tumors, such as those of the parotid, can improve the diagnosis and treatment of patients.

\section{Conflicts of Interest}

The authors have no conflicts of interest to declare.

\section{References}

1 Stenner M, Klussmann JP. Current update on established and novel biomarkers in salivary gland carcinoma pathology and the molecular pathways involved. European archives of oto-rhinolaryngology: official journal of the European Federation of OtoRhino-Laryngological Societies (EUFOS): affiliated with the German Society for Oto-Rhino-Laryngology -. Head Neck Surg 2009; 266(03):333-341

2 Valstar MH, de Ridder M, van den Broek EC, et al. Salivary gland pleomorphic adenoma in the Netherlands: A nationwide observational study of primary tumor incidence, malignant transformation, recurrence, and risk factors for recurrence. Oral Oncol 2017;66:93-99

3 Bag AK, Curé JK, Chapman PR, Singhal A, Haneef Mohamed AW. Imaging of Inflammatory Disorders of Salivary Glands. Neuroimaging Clin N Am 2018;28(02):255-272

4 Rumboldt Z, Al-Okaili R, Deveikis JP. Perfusion CT for head and neck tumors: pilot study. AJNR Am J Neuroradiol 2005;26(05): 1178-1185

5 Faggioni L, Neri E, Bartolozzi C. CT perfusion of head and neck tumors: how we do it. AJR Am J Roentgenol 2010;194(01): 62-69

6 Tawfik AM, Razek AA, Elhawary G, Batouty NM. Effect of increasing the sampling interval to 2 seconds on the radiation dose and accuracy of CT perfusion of the head and neck. JComput Assist Tomogr 2014;38(03):469-473

7 Bisdas S, Baghi M, Wagenblast J, et al. Differentiation of benign and malignant parotid tumors using deconvolution-based perfusion CT imaging: feasibility of the method and initial results. Eur J Radiol 2007;64(02):258-265

8 Knopf A, Mansour N, Chaker A, Bas M, Stock K. Multimodal ultrasonographic characterisation of parotid gland lesions-a pilot study. Eur J Radiol 2012;81(11):3300-3305

9 Dong Y, Lei GW, Wang SW, Zheng SW, Ge Y, Wei FC. Diagnostic value of CT perfusion imaging for parotid neoplasms. Dentomaxillofac Radiol 2014;43(01):20130237

10 Wang J, Tang Z, Wang S, et al. Differential diagnostic value of computed tomography perfusion combined with vascular endothelial growth factor expression in head and neck lesions. Oncol Lett 2016;11(05):3342-3348

11 Yang $\mathrm{Z}$, Meng $\mathrm{Q}, \mathrm{Xu} \mathrm{Q}$ et al. Correlation between CT perfusion and vascular endothelial growth factor in neoplasm of head and neck. Zhonghua Fang She Xue Za Zhi 2007;41(09): 900-906

12 Abdel Razek AAK, Mukherji SK. State-of-the-Art Imaging of Salivary Gland Tumors. Neuroimaging Clin N Am 2018;28(02): 303-317

13 Razek AA, Tawfik AM, Elsorogy LG, Soliman NY. Perfusion CT of head and neck cancer. Eur J Radiol 2014;83(03):537-544

14 Truong MT, Saito N, Ozonoff A, et al. Prediction of locoregional control in head and neck squamous cell carcinoma with serial CT perfusion during radiotherapy. AJNR Am J Neuroradiol 2011;32 (07):1195-1201

15 Wang PZ, Yu Q, Shi HM, Luo JC. [Diagnostic value of CT perfusion for parotid gland tumors]. Shanghai Kou Qiang Yi Xue 2005;14 (06):573-577 
16 Tawfik AM, Nour-Eldin NE, Naguib NN, et al. CT perfusion measurements of head and neck carcinoma from single section with largest tumor dimensions or average of multiple sections: agreement between the two methods and effect on intra- and inter-observer agreement. Eur J Radiol 2012;81(10):2692-2696

17 Tawfik AM, Razek AAA, Elsorogy LG, et al. Perfusion CT of head and neck cancer: effect of arterial input selection. AJR Am J Roentgenol 2011;196(06):1374-1380

18 Fischer T, Paschen CF, Slowinski T, et al. Differentiation of parotid gland tumors with contrast-enhanced ultrasound. RoFo Fortschr Geb Rontgenstr Nuklearmed 2010;182(02):155-162

19 Hayano K, Okazumi S, Shuto K, et al. Perfusion CT can predict the response to chemoradiation therapy and survival in esophageal squamous cell carcinoma: initial clinical results. Oncol Rep 2007; 18(04):901-908

20 Ursino S, Faggioni L, Guidoccio F, et al. Role of perfusion CT in the evaluation of functional primary tumour response after radiochemotherapy in head and neck cancer: preliminary findings. $\mathrm{Br} \mathrm{J}$ Radiol 2016;89(1065):20151070

21 Trojanowska A, Trojanowski P, Drop A, Jargiełło T, Klatka J. Head and neck cancer: value of perfusion $\mathrm{CT}$ in depicting primary tumor spread. Med Sci Monit 2012;18(02):CR112-CR118

22 Trojanowski P, Klatka J, Trojanowska A, Jargiełło T, Drop A. Evaluation of cervical lymph nodes with CT perfusion in patients with hypopharyngeal and laryngeal squamous cell cancer. Pol J Radiol 2011;76(01):7-13 